DOI: http://dx.doi.org/10.22201/iie.18703062e.2006.88.2399

\author{
PABLO F. AMADOR MARRERO
}

\title{
Dos cobres del pintor novohispano Antonio Sánchez en Canarias
}

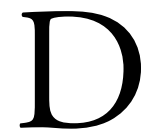

EBIDO A SU PARTICULAR ENCLAVE GEOGRÁfiCo, el Archipiélago Canario, última escala antes de surcar las aguas atlánticas en la ruta de Indias, mantuvo una estrecha relación con el Nuevo Mundo. Uno de los más claros exponentes de este vínculo es sin duda el arte, lo que ha implicado que a lo largo de los siglos las Islas atesoren en sus templos y colecciones un representativo número de obras de los diferentes centros productores americanos. Entre ellas destacan, tanto por número como por calidad, las piezas remitidas desde la Nueva España, con cuyos puertos de Campeche y Veracruz hubo, ya desde el siglo Xvi, un continuo intercambio. Dicho legado —en su mayor parte recuerdo perenne de los emigrantes insulares - se ha dado a conocer en diferentes estudios donde se establecen acertadas catalogaciones pictóricas, ${ }^{\mathrm{I}}$ junto a otras que hasta el momento presentan ciertas interrogantes. Dos de estos casos son los que ahora nos ocupan. Se trata de dos láminas de cobre, ambas de colecciones particulares de Tenerife, pintadas al óleo, rubricadas por Anto-

I. Para obtener mayor información sobre el tema véase, Domingo Martínez de la Peña, "Pinturas mexicanas del siglo Xviı en Tenerife", Anuario de Estudios Atlánticos, Madrid-Las Palmas, Patronato de la Casa de Colón, núm. 23, 1977, pp. 583-60I; "Escultura y pintura americana en Canarias", en Canarias y América. Gran enciclopedia de España y América, Madrid, Espasa-Calpe/Argantonio, 1988, pp. 213-224; Carmen Fraga González, "Nueva relación de pinturas mexicanas en Canarias", en V Coloquio de Historia Canario-Americana (1982), Las Palmas de Gran Canaria, 1985, t. I, 2a. parte, pp. 887-908; Pablo Francisco Amador Marrero, "La travesía artística entre Canarias y América", en Traza española, ropaje indiano. El Cristo de Telde y la imaginería en caña de maíz, Gran Canaria, Ayuntamiento de Telde, 2000, pp. 13-23. 


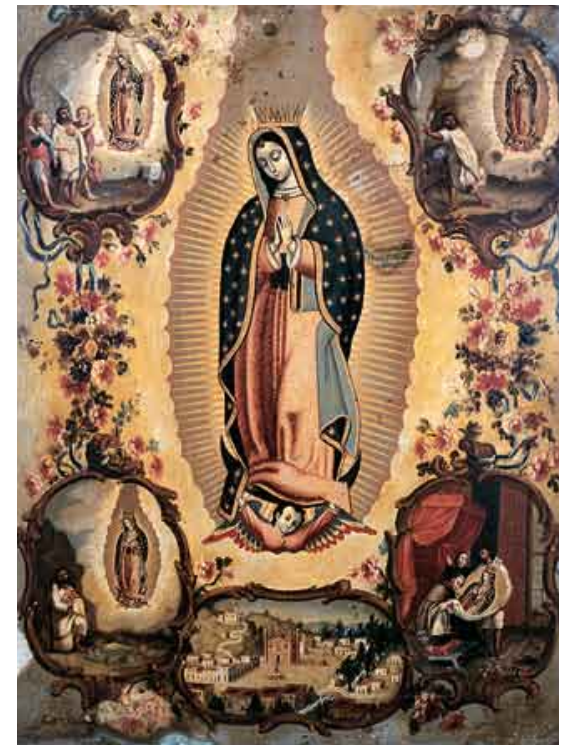

I. Antonio Sánchez, Virgen de Guadalupe, ca. I770, óleo sobre lámina de cobre, $44 \times 33 \mathrm{~cm}$. Colección particular, Tenerife, España.

Foto: Fernando Cova del Pino.

nio Sánchez y relativas a temas marianos: la Virgen de Guadalupe (fig. I) una y la Virgen de la Providencia (fig. 2) la otra. La primera ya fue dada a conocer dentro de un estudio monográfico de la pintura canaria durante la centuria del setecientos, donde se la relacionó con Antonio Sánchez González (I758-1826), artista canario discípulo de Juan de Miranda y Cejas, máximo exponente de la pintura insular de ese siglo. ${ }^{2}$ Casualmente, con este último se ha suscitado un caso similar a la confusión entre la obra de los Sánchez que ahora resolvemos. Se trata de un lienzo firmado, de mediano formato donde se representa a la Inmaculada, exhibido en el Museo Franz Mayer de México. Hasta la última revisión de los fondos pictóricos de esta institución realizada por la investigadora Rebeca Kraselsky, la obra figuraba como pieza canaria. Finalmente, la referida estudiosa pudo corregir la atribución mantenida gracias a la asesoría de la catedrática

2. Margarita Rodríguez González, La pintura en Canarias durante el siglo XVIII, Canarias, Cabildo Insular de Gran Canaria, 1986, p. 469. El mismo cuadro fue nuevamente analizado en Margarita Rodríguez González, Sacra memoria. Arte religioso en el Puerto de la Cruz, Tenerife, 2000, p. 133 (catálogo de exposición). Queremos agradecer a don Juan Zárate su valiosa colaboración. Sobre el artista canario Antonio Sánchez, véase Jesús Hernández Perera, "Antonio Sánchez González, pintor adornista y conspirador", Anuarios de Estudios Atlánticos, Madrid-Las Palmas, Patronato de la Casa de Colón, núm. 3, 1957, pp. 163-204. 
2. Antonio Sánchez, Virgen de la Providencia, ca. I770, óleo sobre lámina de cobre, I05 $\times 86 \mathrm{~cm}$. Colección particular, Tenerife, España. Foto: Fernando Cova del Pino.

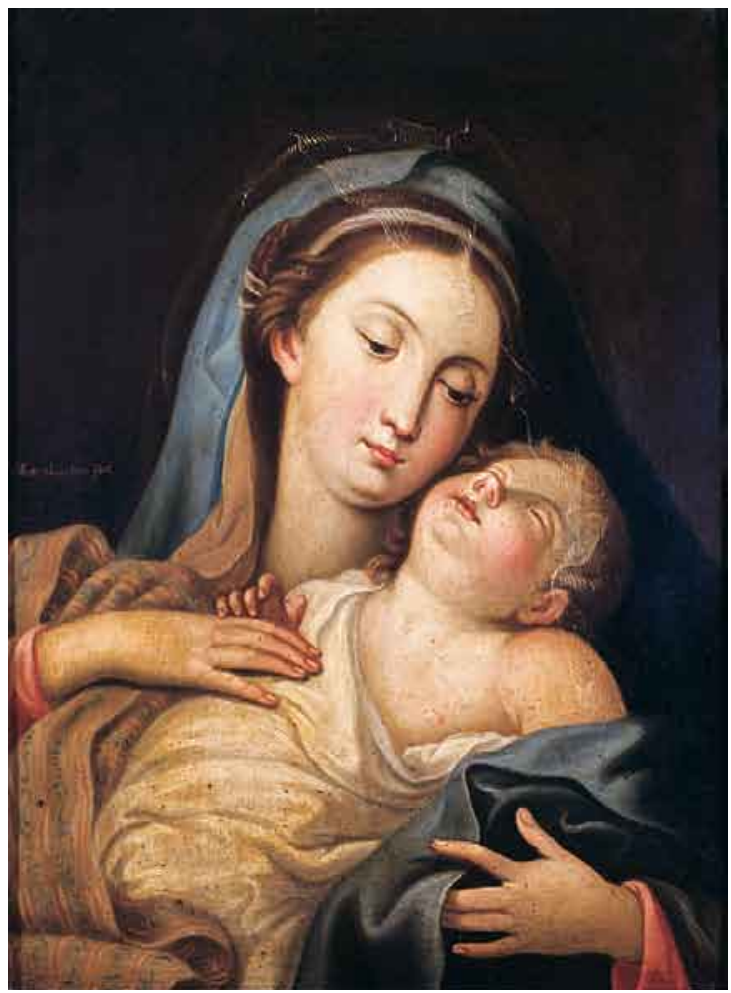

Margarita Rodríguez González de la Universidad de La Laguna, Islas Canarias; hoy sabemos que se trata en realidad del artífice novohispano de igual nombre que laboró en México durante el siglo XviII.

La citada lámina plúmbea, de $44 \times 33 \mathrm{~cm}$, describe la tradicional representación de Nuestra Señora del Tepeyac a modo de vera efigie inserta en su almendra dorada. En cada vértice encontramos las habituales apariciones o mariofanías, influencia directa que en cuanto al mismo tema ejerciera en numerosas ocasiones Miguel Cabrera, y de los grabados ejecutados por Matías de Arteaga y Alfaro, tan comunes de esta iconografía y que en la obra que abordamos quedan insertas en rocallas a modo de marcos. Bajo la efigie mariana, y también circundado por rocallas, hay un minucioso paisaje del Tepeyac con varias edificaciones y santuarios, que ha de ponerse en relación con el deseo de la Virgen de que en aquel lugar, donde se le apareció al indio Juan Diego, se erigiera su templo. El resto de la composición se complementa con una profusa labor de decoración a base de cintas 


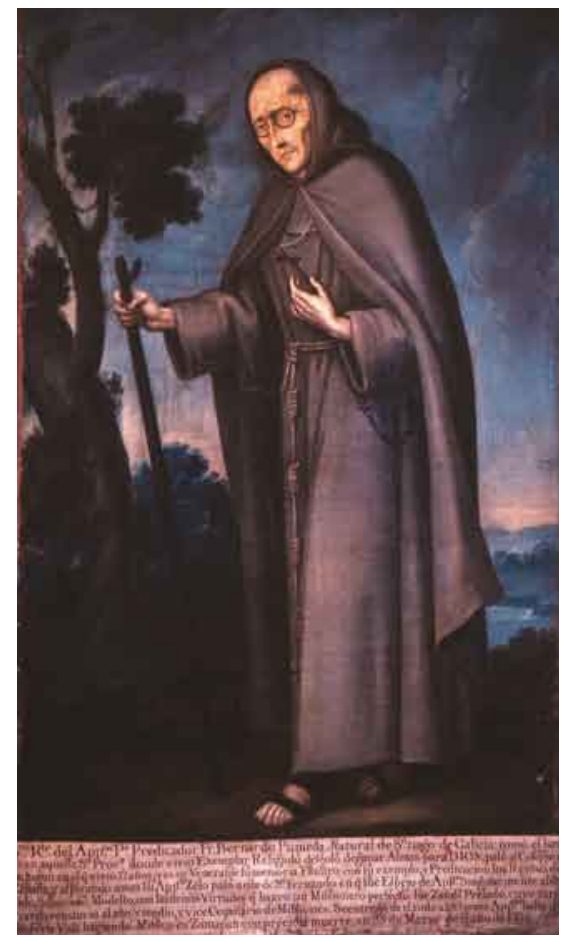

3. Antonio Sánchez, Verdadero retrato de fray Bernardo Pumeda, segunda mitad del siglo xviII, ex convento de San Francisco, ciudad de México. Foto: Pedro Ángeles, Archivo Fotográfico IIE-UNAM.

y flores, estas últimas de estrechos vínculos simbólicos con las apariciones. En el ángulo inferior izquierdo queda recogida la signatura de su artífice, cuya particular abreviatura y grafía nos remite directamente a algunas de sus obras mexicanas, como por ejemplo el gran lienzo El triunfo de la Trinidad ubicado sobre la entrada de la sacristía del templo del Carmen, ciudad de México, rubricado y firmado por su autor en $1772 .^{3}$ Otras obras firmadas por Antonio Sánchez, que poseen casi idénticas signaturas, son los retratos de cuerpo entero de los frailes franciscanos Bernardo Pumeda (fig. 3) y Diego Alcántara (fig. 4), pertenecientes al ex convento de San Francisco, ciudad de México, donde se nos muestra a un artista docto en su arte y fiel exponente de la pintura dieciochesca mexicana. ${ }^{4}$ Esta relación de

3. Elisa Vargaslugo et al., Parábola novohispana. Cristo en el arte virreinal, México, Fomento Cultural Banamex, 2000, pp. 156-I57.

4. Queremos agradecer al maestro Pedro Ángeles Jiménez, coordinador del Archivo Fotográfico Manuel Toussaint del Instituto de Investigaciones Estéticas de la UNAM, el habernos facilitado las referencias sobre estos dos nuevos lienzos. 
4. Antonio Sánchez, Verdadero retrato de fray Diego de Alcántara, segunda mitad del siglo XVIII, ex convento de San Francisco, ciudad de México. Foto: Pedro Ángeles, Archivo Fotográfico IIE-UnAM.

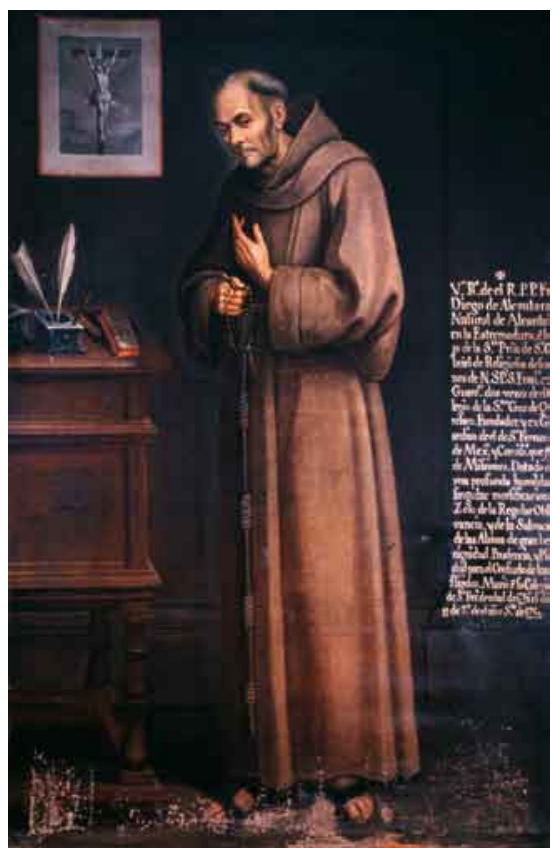

firmas viene a descartar la hipotética filiación de la obra que ahora estudiamos respecto a su homónimo canario, y queda así demostrada su realización novohispana para sumarse al rico acervo que del mismo tema se conserva en las Islas, algunas de ellas signadas por artífices mexicanos tan destacados como Luis Berrueco, José Guerrero o José de la Cruz..$^{5}$ A la vez, hemos de señalar que, a la hora de elegir el soporte para sus obras, los pintores canarios no recurrieron a la técnica del óleo sobre cobre, como sí lo hicieron los artífices mexicanos, tal cual queda demostrado por el alto número de obras conservadas, algunas de ellas firmadas por Luis Juárez, Baltasar de Echave Ibía, Alonso López de Herrera, Cristóbal de Villalpando y Nicolás Enrique, entre otros. ${ }^{6}$ También de Antonio Sánchez se conservan algunos ejemplos sobre lámina de cobre como los que actualmente

5. Para conocer mayor información, véase Carlos Rodríguez Morales, Guadalupe. Itinerarios iconográficos de una devoción, Tenerife, Caja Canarias, Obra Social y Cultural, 2003.

6. Sobre este tema, véase Clara Bargellini, "Painting on Copper in Spanish America", en Copper as Canvas. Two Centuries of Masterpiece Paintings on Copper, 1575-1775, Phoenix, Phoenix Art Museum, 1999, pp. 3I-44. 


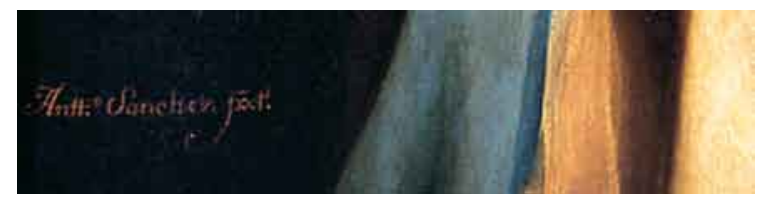

5. Antonio Sánchez, detalle de la firma, Virgen de la Providencia, ca. I770, óleo sobre lámina de cobre, I05 $\times 86 \mathrm{~cm}$. Colección particular, Tenerife, España. Foto: Fernando Cova del Pino.

se exhiben en el Museo Regional de Guadalajara, dando fe del conocimiento y gusto que el pintor mostró por esta técnica. ${ }^{7}$

Caso especial merece la referencia de Manuel Toussaint a un cuadro conservado en una colección particular de México, donde se representa a la Virgen de Guadalupe con las cuatro apariciones, la Santísima Trinidad y dieciocho santos, firmado, aunque sin fecha, por Antonio Sánchez. ${ }^{8}$ El maestro Toussaint lo considera "agradable" y sitúa al autor entre los pintores secundarios del siglo XVIII, anteriores a Ibarra y Cabrera, sin ponerlo en relación con otras piezas signadas por Sánchez también por él conocidas, lo cual nos hace dudar - a la espera de poder corroborar la semejanza de las firmas - de su filiación con nuestro artífice, más aún cuando aquel estudioso mexicano ubica la obra en la primera mitad del siglo, ya que las referencias que tenemos de Antonio Sánchez lo emplazan entre 1769 y 1772.

Respecto al otro cobre, éste representa la iconografía conocida como Virgen de la Providencia, de $105 \times 86 \mathrm{~cm}$, donde en una escena maternal se muestra a la Virgen al contemplar y arropar al niño Jesús, plácidamente dormido en los brazos de la madre. Esta obra, que ya dimos a conocer con motivo de la exposición Sacra memoria. Arte religioso en el Puerto de la Cruz, ${ }^{9}$ pese a encontrarse firmada con idéntica rúbrica (fig. 5) que el caso anterior de la Virgen de Guadalupe (fig. 6), propició en su momento serias dudas a la hora de plantearse sus vínculos con la escuela pictórica mexicana y, por consiguiente, con la atribución del cobre guadalupano. ${ }^{\mathrm{IO}}$ Dicha confusión, debida a la referencia de Toussaint

7. Ibid., p. 4I, y también Manuel Toussaint, Pintura colonial en México, México, Universidad Nacional Autónoma de México-Instituto de Investigaciones Estéticas, I990, p. I87.

8. Toussaint, op. cit., p. I54.

9. Margarita Rodríguez González, Sacra memoria..., op. cit.

ı. Margarita Rodríguez González, "Virgen con el Niño dormido", en Sacra memoria..., op. cit., p. II2. 


\section{Antonio Sánchez, detalle de la firma, Virgen de Guadalupe, ca. 1770, óleo sobre lámina de cobre, $44 \times 33 \mathrm{~cm}$. Colección particular, Tenerife, España. Foto: Fernando Cova del Pino.}

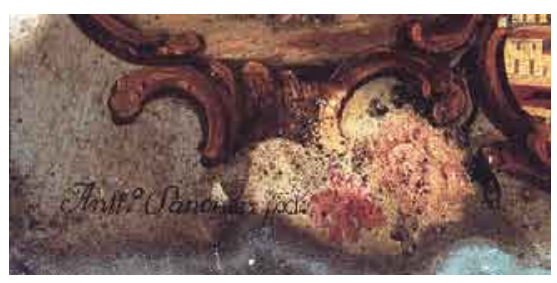

sobre Antonio Sánchez, queda ahora despejada por el estudio de las firmas, pues se ha demostrado que se trata de una obra de un estilo más avanzado respecto a las pautas de la primera mitad del siglo XviII, donde situaba Toussaint la lámina por él analizada. ${ }^{\text {II }}$ Cierto es que si la pieza hubiese sido realizada por el pintor canario, perfecto conocedor de los postulados ilustrados y neoclásicos en los cuales se desenvolvió, la composición podría remitirnos a referencias quinientistas y, por ende, setecentistas, como indica la profesora Rodríguez González. ${ }^{12}$ Pero en este caso consideramos que la lámina hubo de ser realizada con base en algún grabado de importación que circuló en tierras novohispanas durante la segunda mitad del siglo XviII, y que reprodujo con acierto nuestro artífice.

La catalogación de esta obra como de procedencia indiana nos hace a la vez plantear la atribución de dos nuevas piezas idénticas en cuanto a materiales, iconografía y factura. La primera de ellas la encontramos inserta en el segundo cuerpo del actual retablo del Sagrado Corazón de la anteriormente referida iglesia del Carmen, donde, como vimos, se conserva el gran lienzo de la Trinidad realizado por Antonio Sánchez en I772. Ello puede llevarnos a suponer que nuestro artífice realizó diversos encargos para el mismo templo y a partir de ello proponer una aproximación cronológica de los cobres. Así, sostenemos que la lámina canaria ha de fecharse en torno a la década de los setenta del siglo XVIII, cerca de la realización del lienzo reseñado y, por tanto, del cobre homónimo del mismo templo.

Respecto a la otra lámina a la que aludíamos, de $63 \times 47 \mathrm{~cm}$, pertenece a los fondos del Museo Nacional del Virreinato, Tepotzotlán, donde figura como obra anónima europea del siglo XVIII. ${ }^{\mathrm{I} 3}$ Aun cuando carece de firma, sus coincidencias con las piezas anteriores son innegables no sólo en el tema, sino también

II. Manuel Toussaint, op. cit., p. I54.

I2. Rodríguez González, op. cit., p. II2.

I3. Roberto Alarcón Cedillo y María del Rosario García de Toxqui (coords.), "Virgen de la Providencia”, en Pintura novohispana, Tepotzotlán, Museo Nacional del Virreinato, 1994, p. IIo. En esta relación la obra aparece con el número de catálogo PI/o3I8. 
DOI: http://dx.doi.org/10.22201/iie.18703062e.2006.88.2399

$2 \mathrm{I} 2$

PABLO F. AMADOR MARRERO

en el modo de ejecución, el trazo del dibujo y la paleta cromática, aunque se distingue de la obra canaria en aspectos puntuales como algunos detalles de pliegues en el manto de la Virgen y el diseño de las cenefas de la misma prenda. Pese a ello, y aunque nada se puede asegurar sin la firma o apoyo documental que pertenezca al mismo autor, nos inclinamos por atribuir la obra a los pinceles de Antonio Sánchez, quien hubo de repetir en varias ocasiones el mismo tema debido posiblemente a la aceptación de una iconografía intimista y moderna. \$ 